\title{
A Coupling Vibration Test Bench and the Simulation Research of a Maglev Vehicle
}

\author{
Weihua Ma, ${ }^{1,2}$ Rongrong Song, ${ }^{3}$ Junqi $\mathrm{Xu},{ }^{4}$ Yu Zang, ${ }^{1}$ and Shihui Luo ${ }^{1}$ \\ ${ }^{1}$ Traction Power State Key Laboratory, Southwest Jiaotong University, Chengdu 610031, China \\ ${ }^{2}$ CSR Qishuyan Locomotive Co., Ltd., Changzhou 213011, China \\ ${ }^{3}$ College of Computer Science and Technology, Southwest University for Nationality, Chengdu 610041, China \\ ${ }^{4}$ Maglev Transportation Engineering R\&D Center, Tongji University, Shanghai 201804, China
}

Correspondence should be addressed to Weihua Ma; maweihua2008@gmail.com

Received 12 February 2014; Revised 2 July 2014; Accepted 2 October 2014

Academic Editor: Hamid Hosseini

Copyright (C) 2015 Weihua Ma et al. This is an open access article distributed under the Creative Commons Attribution License, which permits unrestricted use, distribution, and reproduction in any medium, provided the original work is properly cited.

\begin{abstract}
To study the characteristics of the coupling vibration between a maglev vehicle and its track beam system and to improve the performance of the levitation system, a new type of vibration test bench was developed. Take a single maglev frame as the study object; simulation of the coupling vibration of the maglev vehicle, levitation system, and track beam were achieved. In addition, all types of real track irregularity excitations can be simulated using hydraulic actuators of the test bench. To expand the research scope, a simulation model was developed that can conduct the simulation research synergistically with the test bench. Based on a dynamics model of the test bench, the dynamics simulation method determined the influence on the levitation control performance of three factors: the track beam support stiffness, the track beam mass, and the track irregularity. The vibration resonance phenomenon of the vehicle/track system was reproduced by the dynamics simulation, and a portion of the simulation results were validated by the test results. By combining the test bench and the dynamics model, experiments can be guided by the simulation results, and the experimental results can validate the dynamics simulation results.
\end{abstract}

\section{Introduction}

Currently, with requirements growing for the diversification of transportation, increasing numbers of research studies of maglev trains are being performed [1-16]. Many test lines for maglev trains are being constructed. A high-speed maglev train test line has been constructed in Germany, a high-speed maglev train commercial demonstration line has been constructed in China, and commercial low-speed maglev train lines have been built in both Japan and Korea. Some middleand low-speed maglev train test lines are under construction in China, and middle- and low-speed maglev train service lines are in the planning stage in cities such as Shenzhen and Changsha [17-20]. Although maglev train technology has been developing rapidly and some maglev train commercial lines have been built, some problems remain in middle- and low-speed maglev train research, such as the reduction of the levitation force, vagueness of market positioning, and high cost. These problems make the market prospects of middle- and low-speed maglev trains unclear; as a result, these problems must be urgently addressed. Resonance vibration affecting the mechanical structure, levitation control system, and track beam has been one of the troublesome problems of maglev train research. In addition, laboratory simulation of the electromechanical coupling vibration of a maglev train is another complex problem.

Many coupling vibration phenomena between a maglev train and the track have been observed during maglev research and development. During research for the Japanese HSST (high speed surface transportation) series low-speed maglev train, the maglev levitation module exhibited oscillation vibration due to the low stiffness of the supporting track beam. The German TR (transrapid) series high-speed maglev train could perform levitation steadily on a track with a concrete holder but not on a track with a steel holder. Both the AMT (American management technology) series maglev train and the Korean UTM (urban transit maglev) series maglev train experienced a coupling vibration problem 
between the train and the track; this occurred also on the maglev train of China. This coupling vibration phenomenon between the vehicle and track beam is the key problem during development and service of a maglev train [1-6]. In the early stages, the Bernoulli-Euler track beam model was usually adopted by researchers. In this model, the influence of the simply supported beam, the mass ratio between the maglev vehicle and the track, the supporting stiffness of the track beam, and the levitation stiffness of the maglev vehicle system dynamics are modelled by representing the maglev vehicle as a movement force or a movement mass block [1]. The maglev train dynamics model has undergone continuous improvement since the 1990s [2-8]. There are a few studies of the interactions of the vehicle/track system, most of which mainly address the hunting stability and curve negotiation of a maglev vehicle on a track with a rigid or flexible structure [9-12]. For example, for the German TR maglev train, one type of maglev vehicle/track interaction model was built by Professor Zhao Chunfa. In this model, the methods of numerical analysis and time-frequency transformation are applied to simulate the random response of the maglev vehicle/track and vehicle/bridge; additionally, the ride index of the TR maglev train is determined using the Sperling index methods [4]. The dynamic characteristics of the maglev vehicle with a two-stage suspension with five degrees of freedom running on an elastic track were analysed in [5]. The simulation result indicated that the elastic characteristics of the track affect the dynamics, and further research on the levitation control parameters has been performed as well.

As is well known, the maglev train system is highly nonlinear and unstable by nature; many types of research studies have been performed since its introduction, including studies of the levitation control system, the design philosophy, and the control parameters. The difference between the electromagnet centralized control method and the dispersive control method was analysed by Gottzein, who proposed that, in the low-speed or static states, levitation stability depends too heavily on the control parameters, while, in the highspeed state, the stability problem is much more complicated because of the influence of the maglev-vehicle/track coupling vibration [13]. The influences of track irregularity on the levitation stability of the maglev train were studied by Sinha, with the system stability of the train under different control methods analysed via the root loci method [14]. Germany and Japan have, respectively, proposed the entire control method on a high-speed and a low-speed maglev train system, and all of the proposed control methods have been applied on a commercial line. After many years of improvement, both methods can be used in practice $[15,16]$.

The mechanical structure and the levitation control system of the maglev train were primarily separated during the above research. Generally, the single electromagnet levitation system was usually taken as the object of study during research on the levitation control system [21], and track beam deformation was only considered as track irregularity, which can hardly reflect the nature of the track beam. Additionally, because the maglev vehicle model was oversimplified, some characteristics of the maglev vehicle were ignored. In contrast, most research on the vehicle dynamics that focus on

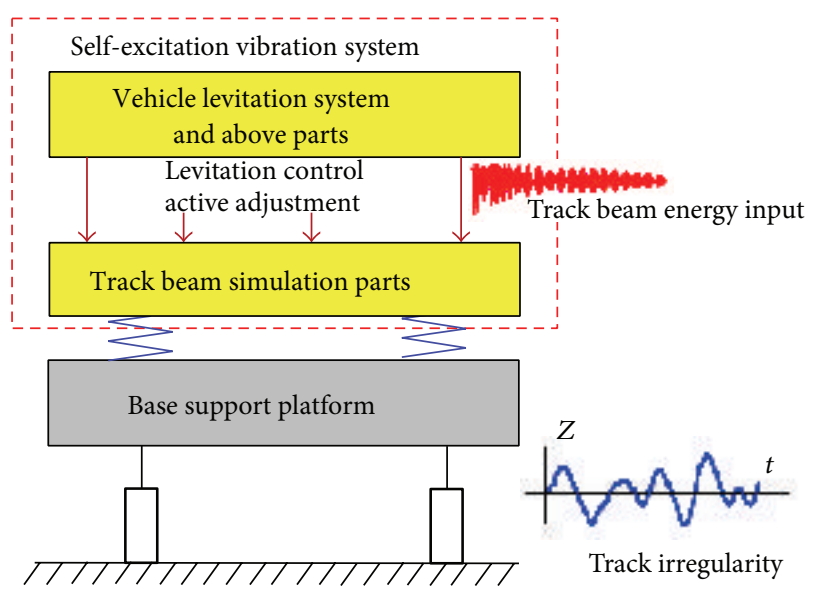

Figure 1: Principle of the test bench.

the coupling vibration of the vehicle/track beam system mainly studies the mechanical aspects and loses sight of the levitation control system; there are only a few special research studies that focus on the resonance vibration in the static state of the maglev vehicle. The complex vibration phenomenon cannot be properly understood without considering the levitation-frame/track-beam/levitation-control systems together. As a result, the relationships among support stiffness, levitation mass, and levitation stability cannot be reflected without considering the entire system [22-24].

In this paper, the mechanical structure and electrical system are combined, resulting in the creative construction of an electromechanical coupling vibration test bench. Considering the mechanical structure, the track beam, and the levitation control system together, the electromechanical coupling vibration test was realised in the laboratory using the developed test bench. Furthermore, a dynamics simulation model of the test bench was built as a supplement.

\section{Principle of the Test Bench}

In the design stage of the maglev vehicle electromechanical coupling vibration test bench (hereafter, the test bench), the characteristics of the vehicle structure, track beam, and levitation control system were to be considered simultaneously. However, comprehensively considering these factors in a fullscale test bench requires a significant cost and discourages the specific study because of too many uncontrollable factors. Therefore, a scale model is typically used in test bench design.

The test bench in this paper utilized a partial maglev vehicle model, a scale track beam model, and an actual levitation control system. One maglev vehicle consists of 5 levitation frames, each of which can reflect the characteristics of the maglev vehicle. Therefore, a single levitation frame was used as the research object for simplicity.

Figure 1 shows the principle of the test bench. The mass of the levitation system and the parts of the maglev vehicle above it are treated as the levitation mass (simply called the maglev vehicle levitation module). This is coupled with the track beam simulation system through the levitation control system. The track beam simulation part is set on 


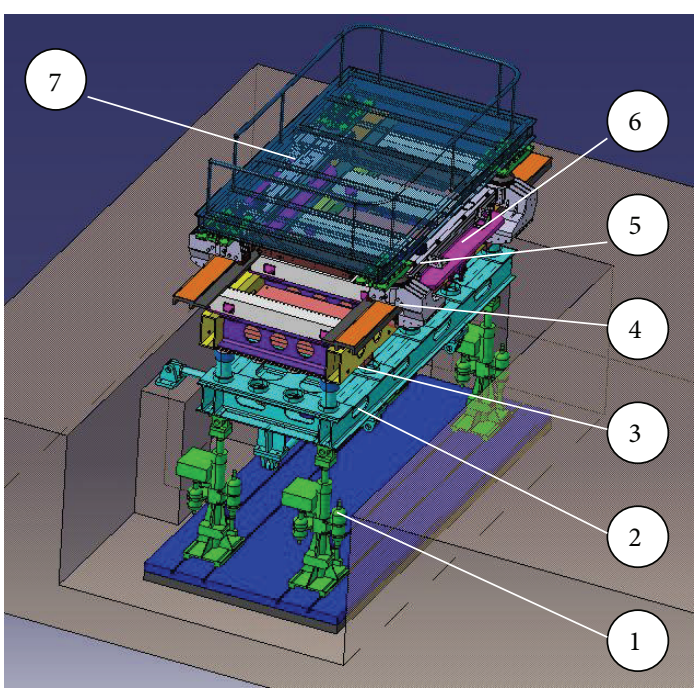

(a) Design project of the test bench

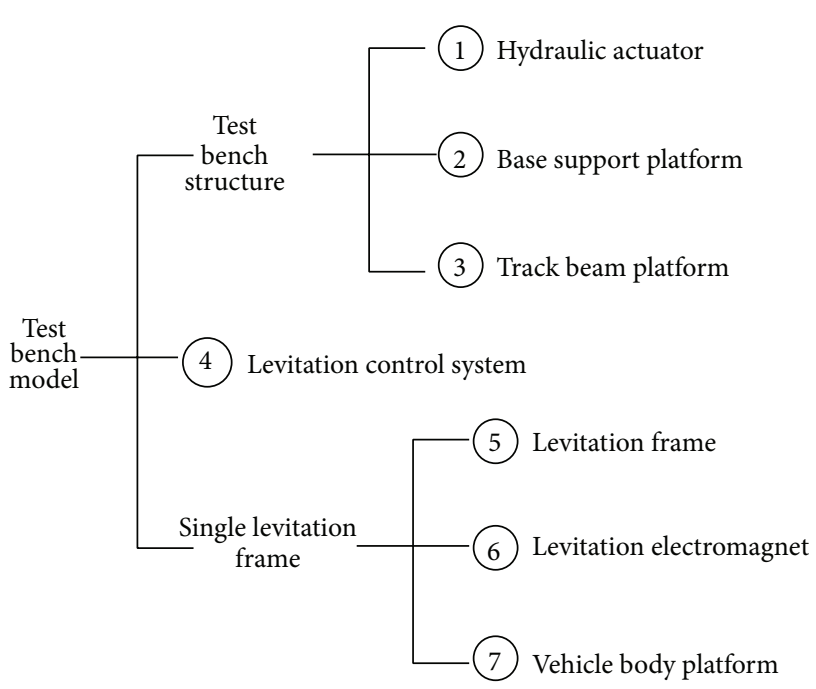

(b) Main departments of the test bench

Figure 2: Project of the test bench and the main departments.

a support platform by supporting springs; the support platform is set on the basic foundation by four hydraulic actuators that can produce a specific track irregularity or provide the specific stimulation under study. The maglev vehicle levitation module acts as an energy input to the track beam system, which forms a self-excitation system. The static-state case of the maglev vehicle can be simulated without using the track irregularity input in the track beam simulation part. In addition, the vibration characteristics of track beam can be simulated by changing the supported mass and the support stiffness of the track beam.

As is well known, the track beam exhibits an inherent frequency; according to its load condition, the track beam can be simply represented as a freely supported beam under a uniform load. The equation of the maximum deflection of the track beam is $Y_{\max }=5 q l^{4} / 384 E I$.

In this formula, $Y_{\max }$ is the maximum deflection that occurs in the medium position of the freely supported beam, $q$ is the standard value of the uniform distribution load, $E$ is the modulus of elasticity, and $I$ is the section moment of inertia.

When the mass of the track beam is fixed, the relationship between deflection and frequency is as follows:

$$
Y=\frac{5 g l^{4}}{384 E I}=\left(\frac{5 g \pi^{2}}{1536 \rho}\right) \cdot\left(\frac{1}{f^{2}}\right)=\frac{k}{f^{2}} .
$$

Here, $g$ is the gravity of the vehicle per meter of vehicle. The relationship between the deflection and frequency is analysed through test and dynamics simulation; it is difficult to formulate an equation between frequency and displacement.

Therefore, the inherent frequency of the track beam can be changed through changing its stiffness, which is an approach similarly used to achieve different deflections of the track beam. By using different mass and stiffness values of the track beam, the frequency response characteristics can be acquired, and research can be performed on the response under variable stiffness and variable frequency. For a track beam with a constant mass, the greater the stiffness, the higher the inherent frequency of the system, and vice versa. For a track beam with constant support stiffness, the larger the mass, the lower the inherent frequency of the system, and vice versa. As a result, research on the characteristics of different track beams can be performed by changing the mass and support stiffness values of the beam. In addition, the vibration characteristics between the track beam and the maglev control system can be simulated. The matching of the track beam and the maglev levitation system enables research on the self-excited vibration, natural frequency, and characteristic frequency of the track beam.

In addition to the characteristics of the track beam, the track irregularity is another factor to be considered. A physical track irregularity will lead to random or periodic stimulation of the maglev train, which can be simulated with a hydraulic actuator. In addition, track beam defects and different positions of the track beam supports will also cause periodic stimulation; this can be simulated by different frequency sinusoidal waves using the hydraulic actuator [25]. In a real maglev vehicle, a mechanical coupling phenomenon exists among the adjacent or the left/right electromagnets; therefore taking one whole levitation frame as the study object can simulate the coupling phenomenon of the entire maglev vehicle. The test bench developed here can perform tests of the levitation control system and the coupling vibration of the mechanical structure; combined with the single levitation frame and levitation control system, it forms a semivirtual and semireal vibration test bench.

\section{Project of the Test Bench}

The project of the test bench is shown in Figure 2, which consists of a single levitation frame system (5), a track beam (3), springs, a base support platform (2), hydraulic 
TABLE 1: Main design parameter of the test bench.

\begin{tabular}{lcl}
\hline Item & Quantity & Parameters \\
\hline T shape groove base foundation & 1 & Mass $10 \mathrm{t}$ \\
Base support platform & 1 & Mass $2.5 \mathrm{t}$ \\
Track beam platform & 1 & Mass $2.4 \mathrm{t} \sim 8.4 \mathrm{t}$ \\
Levitation frame & 1 & Mass $1.5 \mathrm{t}$ \\
Vehicle simulation platform & 1 & Changeable mass \\
Hydraulic actuator & 4 & Maximum force $75 \mathrm{kN}$ \\
Beam support spring & 20 & Stiffness $1 \mathrm{MN} / \mathrm{m}$ \\
Auxiliary rod & 3 & Adopted ball joint \\
\end{tabular}

actuators (1), a basic foundation with a T-shaped groove, and other affiliated devices. The support platform is vertically supported by four hydraulic actuators that stand on the basic foundation. The maximum force of each hydraulic actuator is $75 \mathrm{kN}$; the actuators can simulate many types of regular waves as well as actual measured track irregularities. The maximum acceleration that can be achieved by the hydraulic actuator is no larger than $1 \mathrm{~g}$.

The track beam is set on the support platform by no more than 20 springs, for example, $4 \times 5=20$. Through changing the stiffness and the number of springs, the total supported stiffness can be changed. The mass of the track beam can also be changed by choosing different additional weights, thereby allowing different frequency characteristics of the track beam to be simulated.

Moreover, the track beam system has a preset installation location to match the installation of a high-speed and a lowspeed maglev track beam; that is, the levitation test and track beam characteristics test can be realized through the matching of the test bench and the high-speed or low-speed maglev levitation frame, depending on whether a high-speed or low-speed system is under study.

Because the test bench has a relatively large height, it is installed in a melt pit for the sake of safety and the convenience of adjusting equipment and testing. The support platform is connected to the upright column through one longitudinal pull rod and two lateral pull rods. The hinge joint between the pull rod and support platform is realised by a bolt, and the hinge joint between the pull rod and upright column is realised by bearings. The rod and its soleplate are connected by a ball joint bearing that allows a certain displacement. One function of the pull rod is to prevent the test bench from overturning and to ensure its security. The debugging of the test bench has been completed. The main parameters of the test table are shown in Table 1; Figure 3 shows a photograph of the actual test bench.

The following tests can be conducted by the test bench.

(1) Levitation Control Tests. Analyse the levitation control performance in the state without excitation and compare the characteristics of different levitation control methods. Study the influence on the levitation performance of different control parameters to understand the relationship between

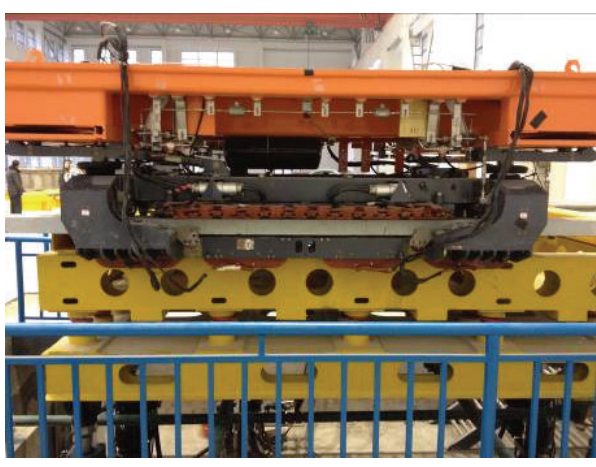

FIGURE 3: Test bench and the levitation frame.

the control parameters, the levitation stability, and the maximum running speed of the maglev train.

(2) Track Irregularity Influence Tests. Study the response of the levitation system to the presence of a track irregularity by analysing the influences of the wavelength and frequency of the track irregularity on the levitation system and determine the limiting values of the wavelength and frequency that the levitation system can tolerate. Analyse the effect of the track irregularity on the vehicle/track coupling vibration. At the same time, analyse the maximum speed of the maglev train with different track irregularities.

(3) Track Beam Characteristics Tests. Through changing the support stiffness and mass of the track beam, conduct research into the impact of beam deflection and of the main frequency characteristics of the beam on vibration of the levitation control system and on the vehicle/track coupling vibration. The test can also be used to optimize selection of the track beam type and to study the influence of the span of the track beam on the levitation control system. Finally, determine the relationships between the different types of track beams, the spans of beams, and the maximum running speeds; the results can then support a theory for the selection of the track beam.

\section{Dynamics Model}

The test bench mainly consists of the basic mechanical structure, the levitation frame mechanical structure, and the levitation control system. During the modelling process, the test bench is separated into the mechanical module and the levitation control system module. The test bench mechanical structure, the single levitation frame, and the levitation control system are modelled separately to create three submodels. Based on the 3 submodels, the single levitation frame mechanical-electrical coupling test bench dynamics model was set up through the substructure method. By separating the mechanical and electric subsystems, the modelling process block diagram can be simplified but also can easily combine the levitation control model and mechanical model. Figure 4 shows the coupling of the levitation control module and the mechanical structure multibody system. 


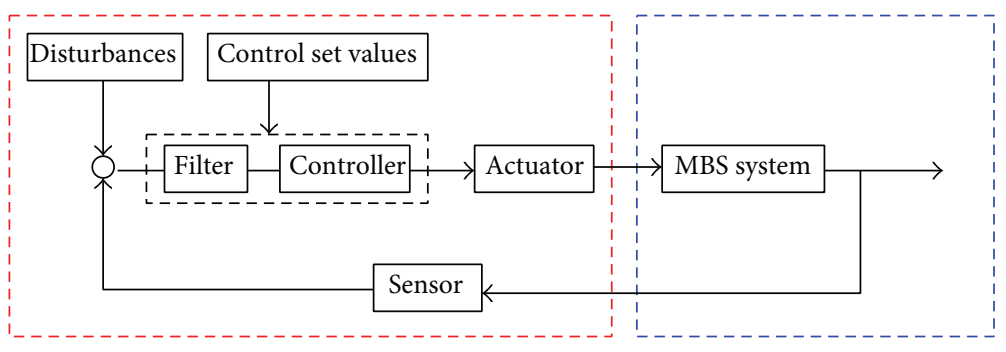

SIMPACK control

SIMPACK MBS

FIGURE 4: Principle of the SIMPACK control system and MBS system.

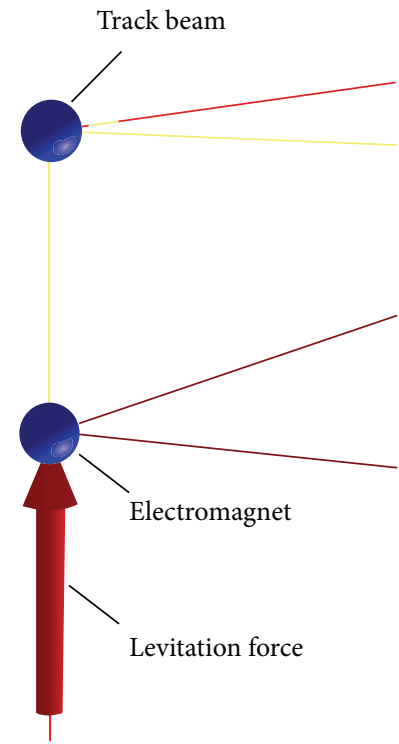

Figure 5: Model of the levitation control point.

The maglev levitation control subsystem is diagrammed in Figure 5, in which the relationship between the maglev levitation control system, track beam, and the electromagnets is represented by two balls and an arrow. The upper ball represents the track beam and the lower ball represents the electromagnet. The separation between the two balls in the original state equals the distance between the electromagnet and track beam when there is no levitation force. The red upward arrow represents the levitation force acting on track beam and the electromagnet. Through the appropriate choice of sensor, filter, and levitation control block diagram, the levitation force can be produced with accurate levitation control. Depending on different demands, different levitation control block frameworks can be selected. One of these levitation control block frameworks is shown in Figure 6. The inputs of each levitation control unit are the relative air gap and the absolute vibration acceleration of the electromagnet, and the output is the levitation force. The control parameters of the test bench are acquired through two methods. Firstly, in previous research we have built a single levitation frame and carried out extensive test research, and through the line test, we obtained many useful parameters. Secondly, we set up a dynamics simulation model of the test bench; many parameters can be acquired though a dynamics simulation. The parameters used in the control method were as follows: $K_{f}=0.0009, T_{1 a}=1.6 \mathrm{~s}, T_{1 b}=0.0016 \mathrm{~s}, T_{h}=0.0008 \mathrm{~s}, T_{d}=$ $0.01 \mathrm{~s}$ (variable), and $I=25 \mathrm{~A}$.

Based on the physical structure of the test bench, the support platform is installed on the basic foundation through four hydraulic actuators that can provide track irregularity excitation. The track beam is set on the support platform using parallel steel coil springs of alterable support stiffness and mass. The support stiffness of the springs and the number of springs can be changed during the test to achieve different support stiffness values of the track beam. A much broader range of support stiffness values can be considered in the dynamics model than in the real test bench. The levitation control system is installed on the single levitation frame and connects the test bench and the single levitation frame through the levitation force. There are two modules in the single levitation frame, each of which has an entire levitation electromagnet system. Each levitation electromagnet system is controlled by two levitation control systems that are installed on the two ends of the electromagnet. As a result, there are 4 control systems in each single levitation frame. The maglev vehicle simulation part is supported on the levitation frame by four air springs; all these items comprise the whole test bench. The test bench dynamics model in SIMPACK software is schematically shown in Figure 7.

\section{Simulation Cases}

Based on the dynamics model of the test bench, a variety of simulations can be performed, including studies of the track beam characteristics and the levitation control test. The simulation provided analyses of the influence of the track beam support stiffness on the levitation control performance. The simulation was also used to determine the effects of the mass of the track beam, the track irregularities, and the track defects on the levitation performance.

5.1. Influence of Support Stiffness. According to the test bench design project, when the stiffness of a steel spring is $1 \mathrm{MN} / \mathrm{m}$, the support stiffness of the track beam can be set to $4,8,12,16$, and $20 \mathrm{MN} / \mathrm{m}$. The levitation performance of the test bench system when the support stiffness is 4 and $20 \mathrm{MN} / \mathrm{m}$ is shown as examples; the results of the levitation gap, levitation force, 


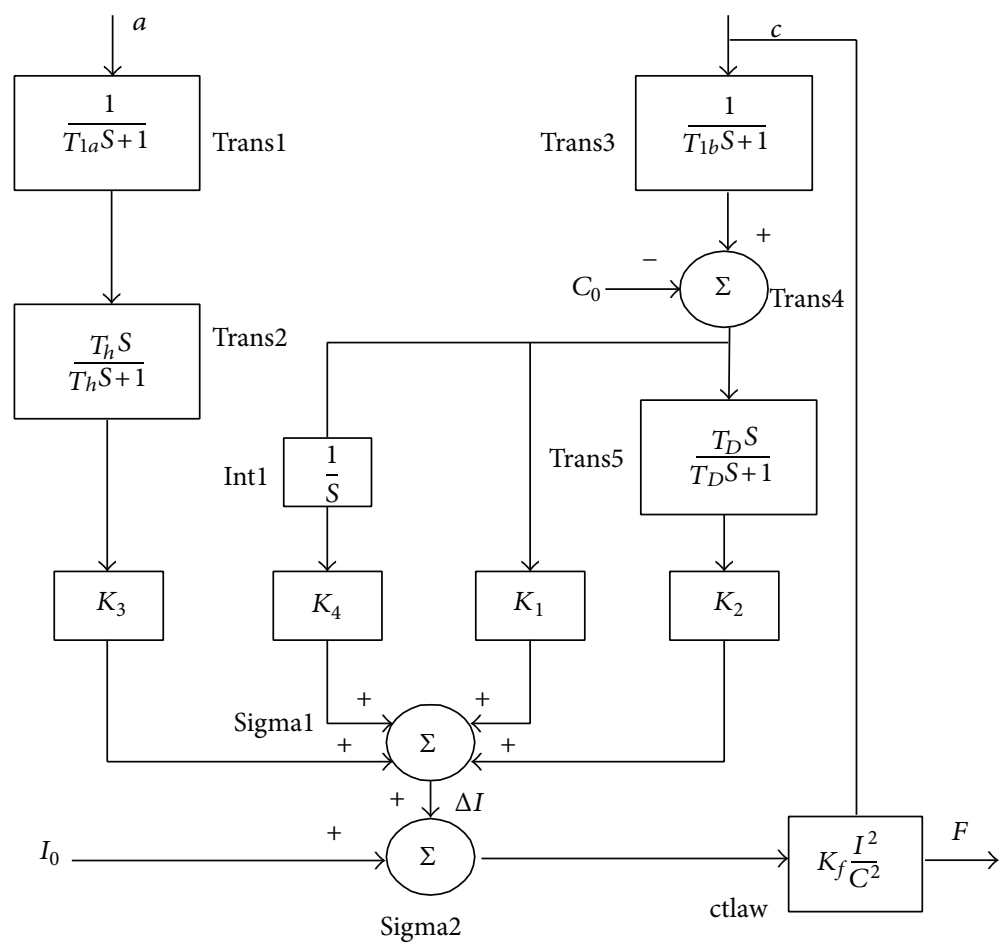

FIGURE 6: Control project framework.

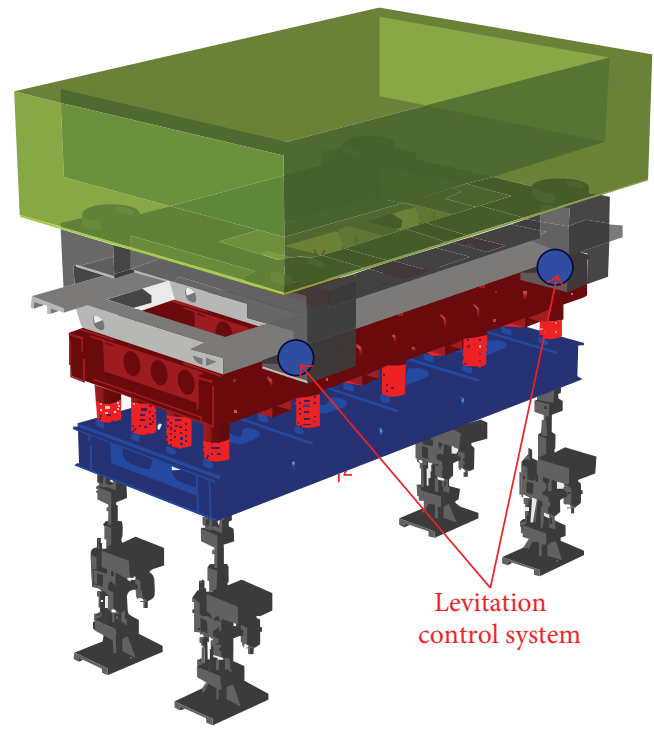

Figure 7: Dynamics model of the test bench.

and vertical vibration of the track beam system with different support stiffness are shown in Figures 8 and 9.

Simulation results indicate that the levitation gap can be maintained at $10 \mathrm{~mm}$ and the vibration of the track beam can converge rapidly in both states when the stiffness value is either $4 \mathrm{MN} / \mathrm{s}$ or $20 \mathrm{MN} / \mathrm{s}$. When the stiffness is $20 \mathrm{MN} / \mathrm{m}$, the vibration amplitude is smaller and the convergence occurs more rapidly than when the stiffness is $4 \mathrm{MN} / \mathrm{m}$, which means the levitation performance is better when the support stiffness of the track beam is $20 \mathrm{MN} / \mathrm{m}$. Under different stiffness conditions, the inherent natural frequency changes; this will also affect the vibration frequency of the electromagnet. The main vibration frequencies of the beam are $2.6 \mathrm{~Hz}$ and $6.8 \mathrm{~Hz}$ when the stiffness is $4 \mathrm{MN} / \mathrm{m}$ and $20 \mathrm{MN} / \mathrm{m}$, respectively.

If matching the mass of the track beam and the support stiffness is not possible, the vibration resonance phenomenon of the vehicle/track will occur during the levitation of the maglev vehicle. For example, when the support stiffness of the track beam is $100 \mathrm{MN} / \mathrm{m}$, the results with a track beam mass of $1000 \mathrm{~kg}$ exhibit oscillations of significant amplitude, as shown in Figures 10 and 11.

Clearly, when the support stiffness of the track beam is $100 \mathrm{MN} / \mathrm{m}$, if the mass of the track beam is light, such as $1000 \mathrm{~kg}$, the vibration of the vehicle/track system cannot converge, resulting in the vibrational resonance phenomenon of the vehicle/track system; this also reappears as the vibration resonance phenomenon of the vehicle/track system in the results of the dynamics simulation.

5.2. Effects of Support Stiffness and Mass of Track Beam. We previously built a low-speed maglev single levitation frame suitable for testing; the parameters of the low-speed maglev line were used for verification. This test was based on the test bench setup to simulate one type of low-speed maglev vehicle levitation frame; the mechanical/electrical coupling vibration test and levitation test were conducted in the static state. Three types of beam mass and beam support stiffness values were compared to analyse the coupling vibration performance of the single levitation frame and the test bench system. 

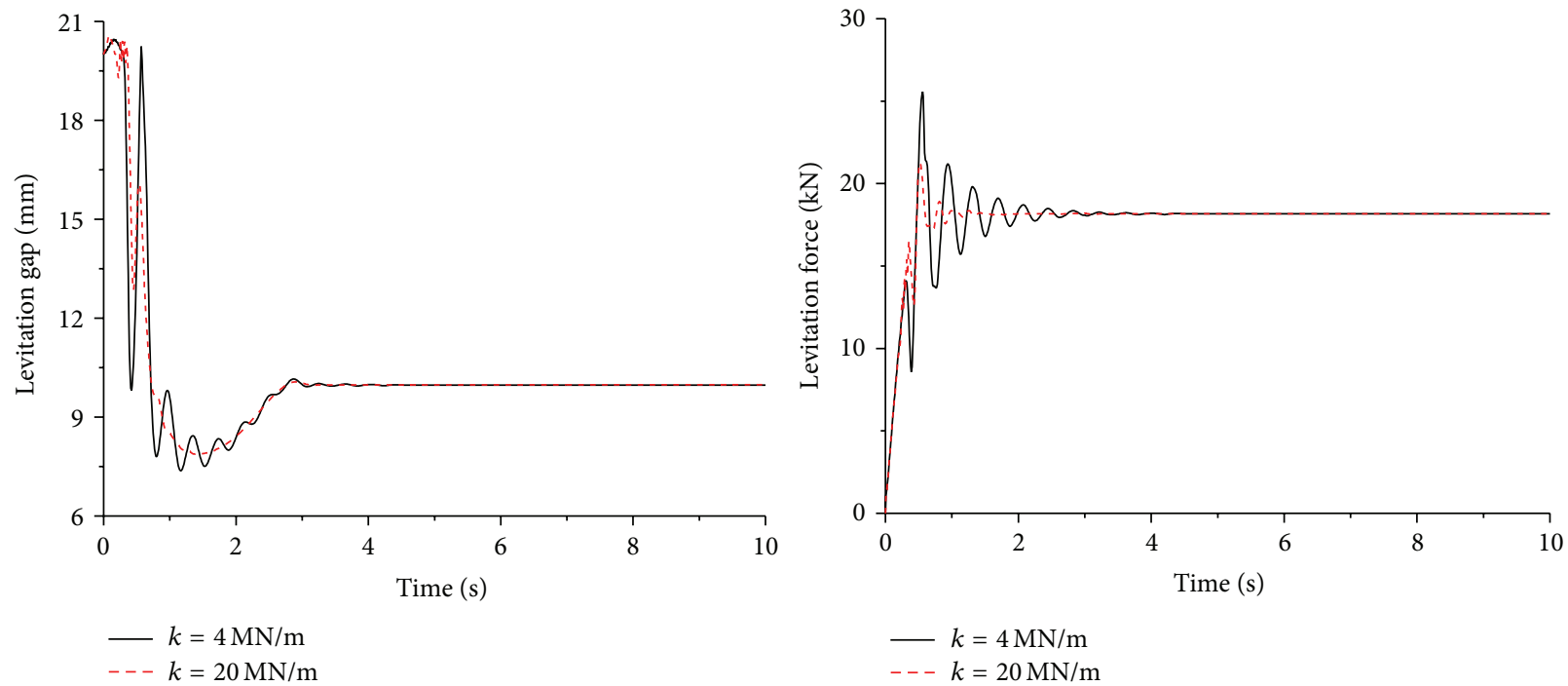

FIGURE 8: Levitation gap and levitation force.
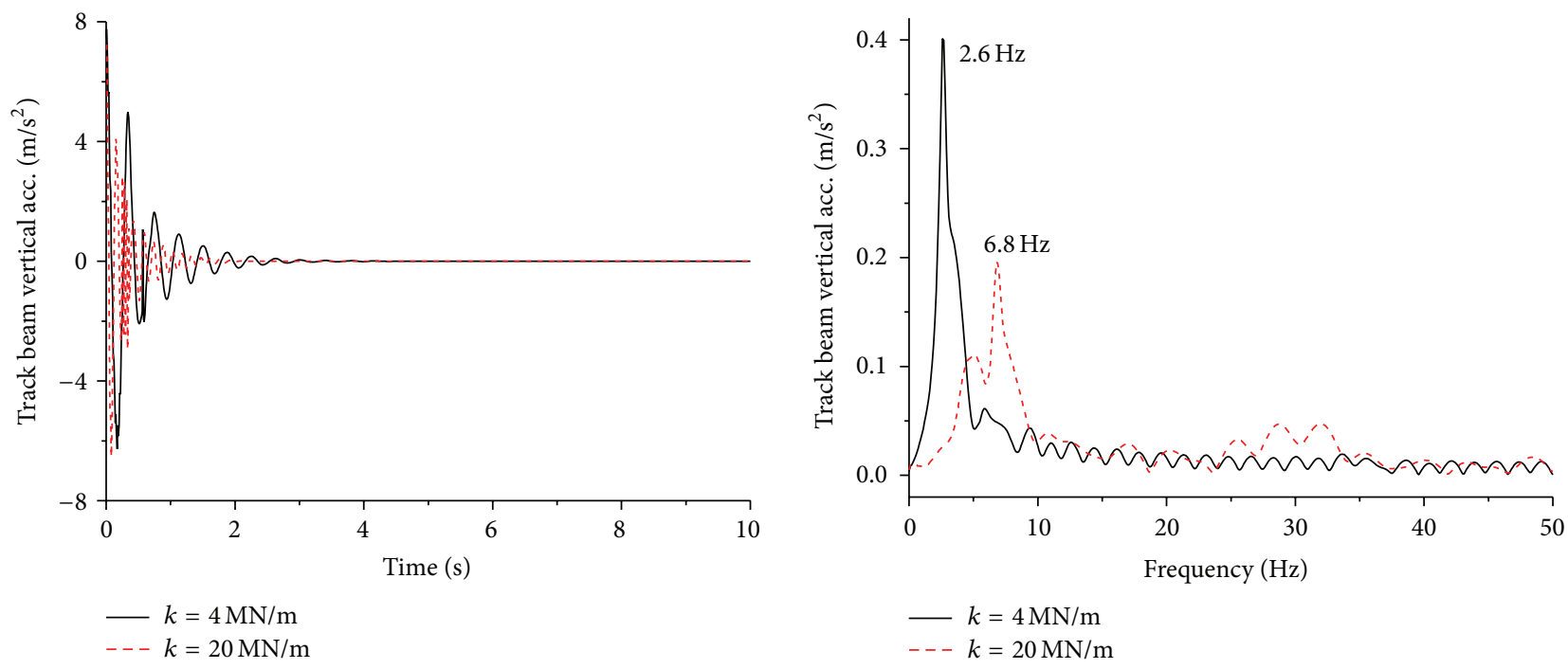

FIGURE 9: Vertical vibration of the track beam and its main frequency.

The track beam weight of an actual low-speed maglev track is $2.7 \mathrm{t} / \mathrm{m}$, and the length of the single levitation frame is approximately $2.8 \mathrm{~m}$. Therefore the total mass of the track beam corresponding to one single levitation frame is approximately $7.5 \mathrm{t}$. Due to the restrictions of the test bench, three beam weights, $2.4 \mathrm{t}, 4.0 \mathrm{t}$, and $5.6 \mathrm{t}$, were chosen for the test. The track beam was supported by 12,16 , and 20 springs for the three beam weights of $2.4 \mathrm{t}, 4.0 \mathrm{t}$, and $5.6 \mathrm{t}$, respectively, and the corresponding stiffness values were $12 \mathrm{MN} / \mathrm{m}, 16 \mathrm{MN} / \mathrm{m}$, and $20 \mathrm{MN} / \mathrm{m}$. The vibration test results of the bracket arm of the levitation frame and track beam system were compared to determine the acceleration and stability of the system in different configurations. The results are presented in Table 2.

Based on the dynamics model of the test bench, the stability performance of the single levitation frame was simulated for each case. The results are shown in Figure 12. Lines with solid points are the simulation results, and those with the open points are the experimental data. The mass of the track beam ranged from $2.0 \mathrm{t}$ to $6.0 \mathrm{t}$ in the simulation.

It can be seen clearly from Figure 12 that the results of dynamics simulation exhibit the same variation trends as the results of experiments. As the mass of the track beam ranges from $2.0 \mathrm{t}$ to $6.0 \mathrm{t}$, the vibration acceleration of the levitation electromagnet and the track beam increases with increasing mass and declines with increasing stiffness.

5.3. Effect of Track Irregularity. The influence of track irregularity on the levitation control system was studied using dynamics simulation; the study considered the examples of the measured track irregularities of the Shanghai maglev 

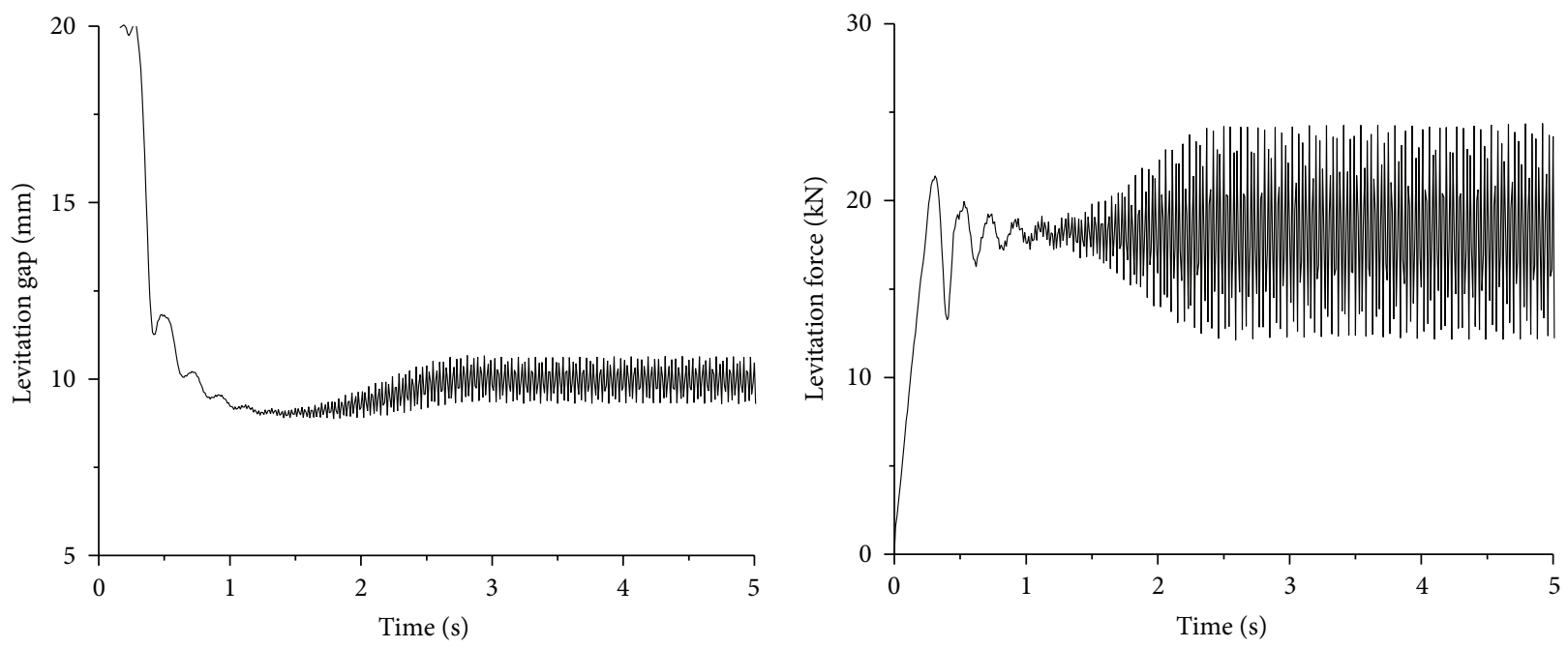

Figure 10: Levitation gap and levitation force.
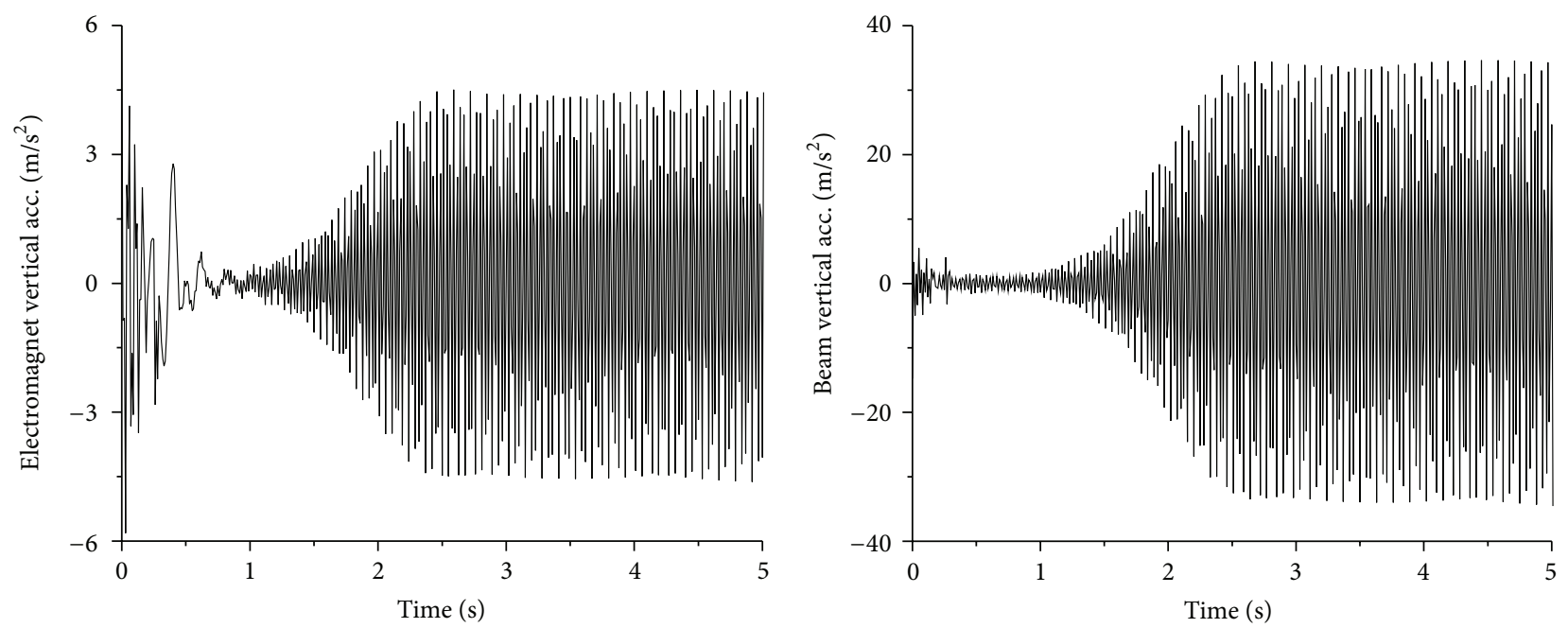

FIGURE 11: Vertical vibration of the electromagnet and track beam.

demonstration line (simply, the Shanghai irregularity) and the German high-speed low disturbance track irregularity (the German irregularity). In these cases, the maglev was statically levitated on the test bench, and the track irregularities were applied through the hydraulic actuators. For testing, the maglev can be stably levitated on the test bench. During the analysis, the track irregularity was first transferred into a time domain track irregularity and then input into the dynamics model through the hydraulic actuators. The Shanghai and German track irregularities are shown in Figure 13. In the model and the simulation, the mass of the track beam was $7.5 \mathrm{t}$ and the track beam support stiffness was $12 \mathrm{MN} / \mathrm{s}$.

5.3.1. Shanghai Measured Track Irregularity. The simulation of the Shanghai track irregularity was performed first, and the results are shown in Figures 14 and 15.
For the Shanghai cases of the measured track irregularity, the levitation gap could be changed with the change of the track irregularity and the value of $10 \mathrm{~mm}$ could be maintained to satisfy the requirement of the levitation control system. The vibration was small for the electromagnet and track beam system, with changes of the vibration acceleration being small and primarily oscillating at the balance position. The results indicate that the levitation control system has good recovery characteristics with the change of track irregularity.

Note that the maglev vehicle cannot transit track with the Shanghai track irregularity in a smooth and steady manner for all levitation control parameter conditions. As clearly seen from the levitation control project in Figure 6, there are 4 main control parameters, $K_{1}, K_{2}, K_{3}$, and $K_{4}$, and all these were used to optimize and implement the levitation system. For the dynamics model of the test bench, the initial values of the control parameters were $K_{1}=3500, K_{2}=4000$, 
TABLE 2: Vibration accelerations of the single levitation frame on different cases.

\begin{tabular}{|c|c|c|c|c|c|c|}
\hline \multirow{3}{*}{ Item } & \multicolumn{6}{|c|}{ Vertical vibration $\left(\mathrm{m} / \mathrm{s}^{2}\right)$} \\
\hline & \multicolumn{2}{|c|}{ Track beam mass $2.4 \mathrm{t}$} & \multicolumn{2}{|c|}{ Track beam mass $4.0 \mathrm{t}$} & \multicolumn{2}{|c|}{ Track beam mass $5.6 \mathrm{t}$} \\
\hline & Electromagnet & Track beam & Electromagnet & Track beam & Electromagnet & Track beam \\
\hline $12 \mathrm{MN} / \mathrm{m}$ & 0.597 & 1.562 & 0.681 & 1.838 & 0.760 & 2.121 \\
\hline $16 \mathrm{MN} / \mathrm{m}$ & 0.458 & 1.161 & 0.521 & 1.343 & 0.598 & 1.652 \\
\hline $20 \mathrm{MN} / \mathrm{m}$ & 0.412 & 0.907 & 0.448 & 0.982 & 0.472 & 1.035 \\
\hline
\end{tabular}

$K_{3}=20$, and $K_{4}=10$. All the control parameters had a large influence on the performance of the levitation control system. The test bench and the single levitation frame system exhibit good levitation performance with the above parameters; the levitation performance will change with the change of the levitation control parameters. Taking $K_{1}$ as an example, different values of $K_{1}$ lead to different levitation performance of the system under the Shanghai track irregularity. The levitation gap of the system with different $K_{1}$ values is shown in Figure 16, where $K_{1}$ changes from 1000 to 4000 in steps of 1000.

From Figure 16, we can clearly see that different $K_{1}$ values have a significant influence on the levitation gap of the system with the Shanghai track irregularity. When the value of $K_{1}$ is 1000 or 2000 , the levitation gap is approximately $20 \mathrm{~mm}$; the design value is approximately $10 \mathrm{~mm}$, so this range of $K_{1}$ cannot satisfy the requirements of the levitation system. However, when $K_{1}$ is between 3000 and 4000, the levitation gap remains steady at $10 \mathrm{~mm}$ and satisfies the requirements.

5.3.2. German Track Irregularity. To compare with the result of the Shanghai track irregularity, the simulation of the German track irregularity used the same simulation conditions as Shanghai track irregularity. The results are shown in Figures 17 and 18.

Comparing the simulation results for the German and Shanghai track irregularities, the results for the German irregularity were worse than those for the Shanghai. Either the change of the scope of the levitation gap and levitation force or the vibration acceleration of the electromagnet and the track beam is greater for the German track irregularity than for the Shanghai. This difference is caused by the fact that the German track irregularity is worse than the Shanghai. In addition, from Figure 13, the change of scope of the German track irregularity is larger than that of the Shanghai. Note that, for both irregularities, the levitation control system exhibits steady performance, and the system can well adapt and satisfy the normal requirements of the maglev vehicle.

5.4. Local Track Support Defect. In addition to the general track irregularity, the track beam may exhibit some local support defects, such as at the connection point of the track. A large vertical irregularity may result from the local support defect, similar to the triangle pitch of railway track or an irregularity at the connect point of the rail. Such irregularities can occur on the track singly or occasionally; generally, periodic irregularities cannot form. The irregularity used in this section is shown in Figure 19; the maximum value of the local vertical defect is $15 \mathrm{~mm}$. To increase the influence of the vertical defect, the case of two consecutive vertical defects was considered, and the response of the test bench system was determined.

The results for two consecutive vertical defects are shown in Figures 20 and 21, which present the results of the levitation gap, levitation force, electromagnet vibration acceleration, and track beam vibration acceleration.

From Figures 20 and 21, for two consecutive vertical defects of $15 \mathrm{~mm}$, the levitation gap and levitation force can change correspondingly to adapt to the urgent track irregularity. Subsequently, the levitation control system can cause the vibration of the system to dampen quickly through the adjustment of the levitation gap and levitation force. This response also demonstrates that the test bench can perform the vertical defect test and that the levitation control system can satisfy the requirements of a $15 \mathrm{~mm}$ vertical defect. Because the levitation gap remains at $10 \mathrm{~mm}$, the maglev train can pass a track connection point with a similar vertical defect without any vehicle-track contact phenomenon.

\section{Conclusions}

A new type of maglev test bench has been developed that can test the coupling vibration of a single levitation frame and the beam. The bench features the combination of the maglev vehicle structure, levitation control system, and characteristics of the track beam. Consider the following.

(1) The test bench can study the maglev vehicle structure, levitation control, and coupling vibration in the laboratory. The bench is an innovation in the maglev area and addresses gaps of maglev train research. The bench can be used to optimize the levitation control project and to analyse the influence of track irregularity. In addition, the bench can be used to study the characteristics of the track beam to provide theoretical support for beam selection, thereby reducing engineering costs.

(2) Based on the test bench, a dynamic model was established. Using the dynamic model of the test bench, the influence of the track beam support stiffness, mass, the track irregularity, and local track support defects on the levitation control performance was studied through the dynamics simulation method, which was used to simulate the vibration resonance phenomenon of the vehicle/track system and to verify some test results. Combining the results of the experiments and the simulations, the experiments can 

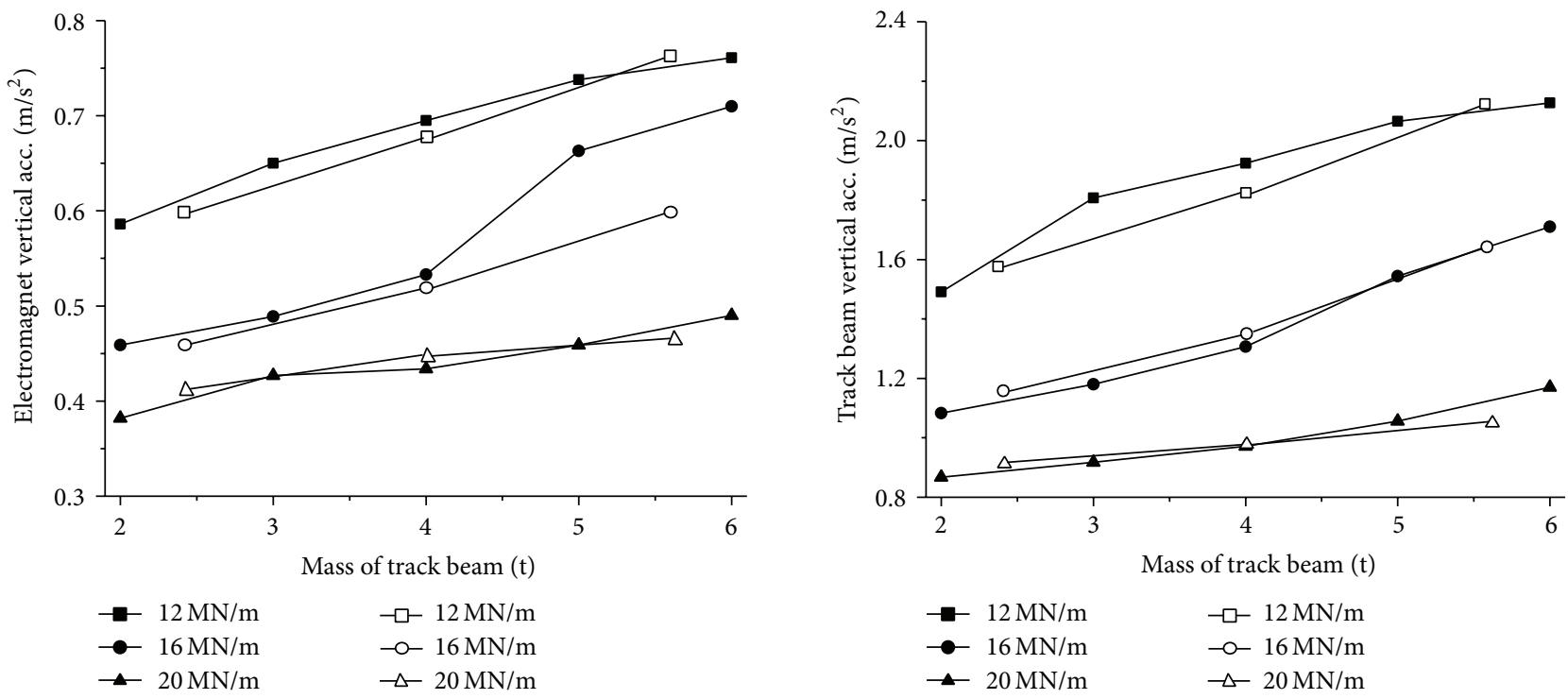

FIGURE 12: Vibration acceleration of the electromagnet and the track beam.
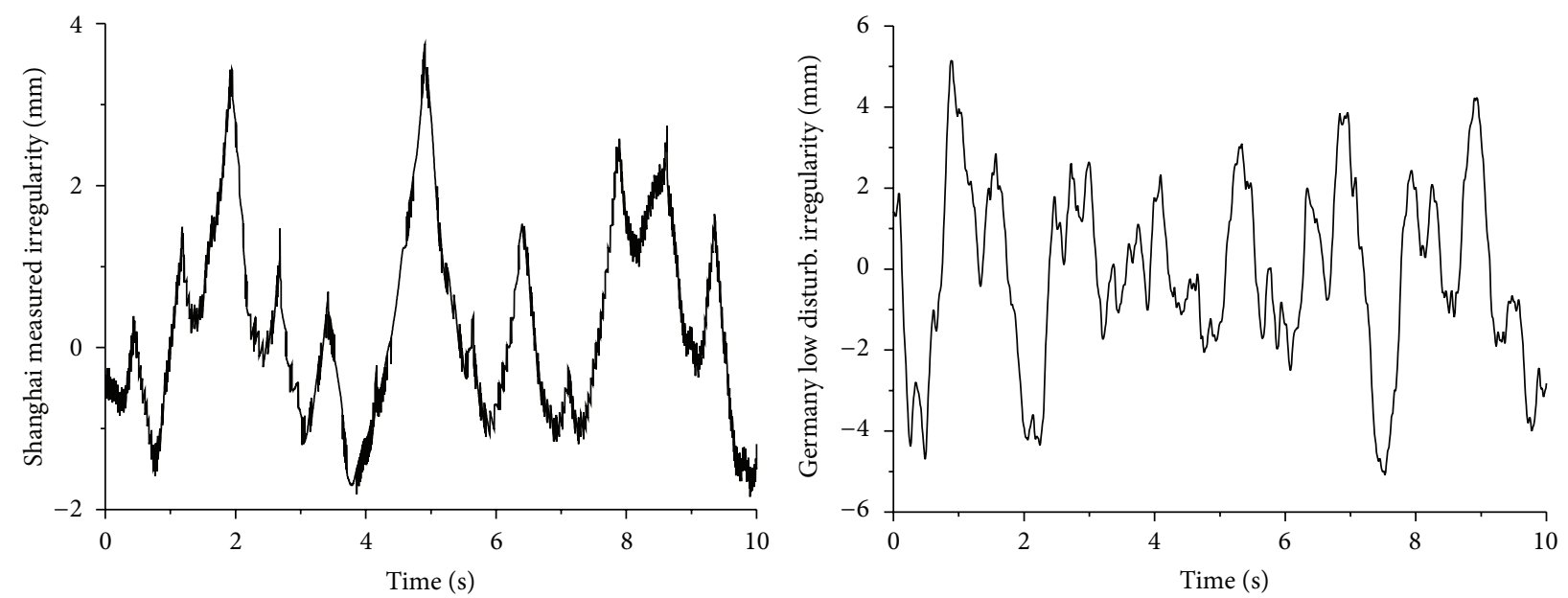

FIGURE 13: The Shanghai measured track irregularity and the German track irregularity.
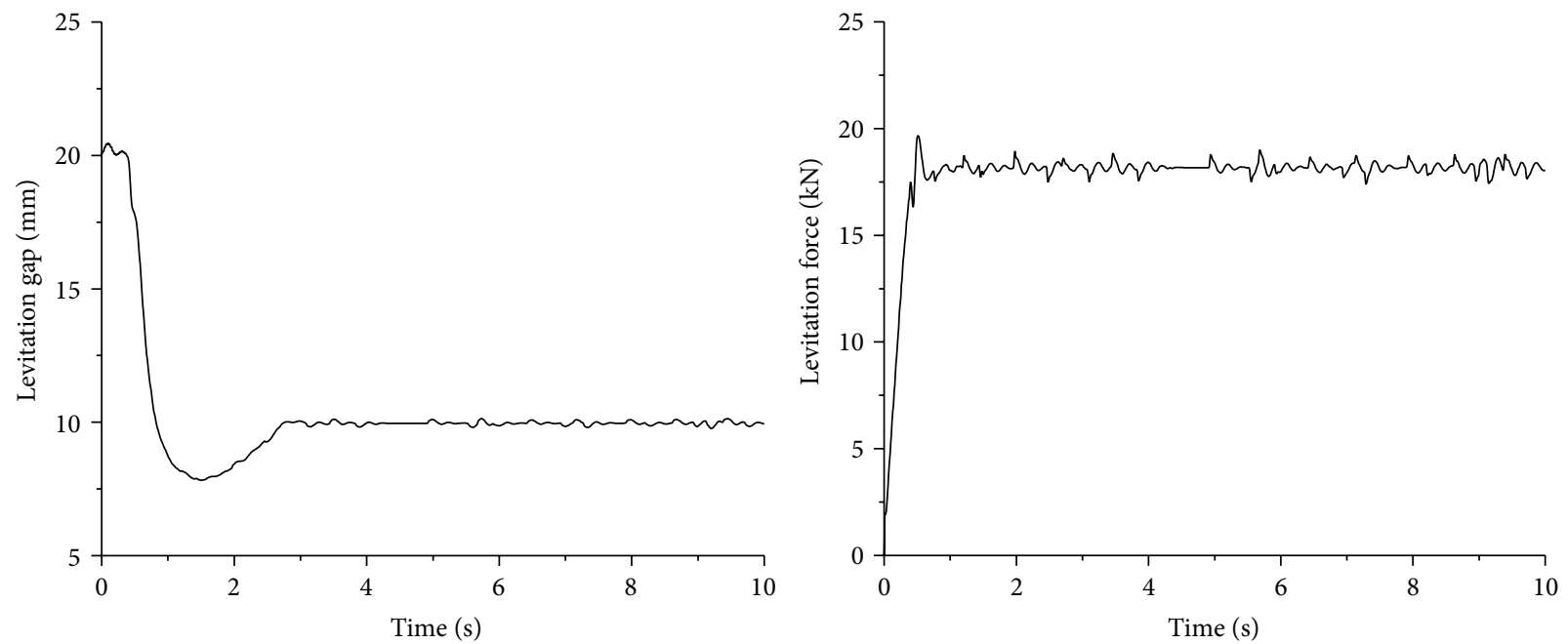

Figure 14: Levitation gap and levitation force. 

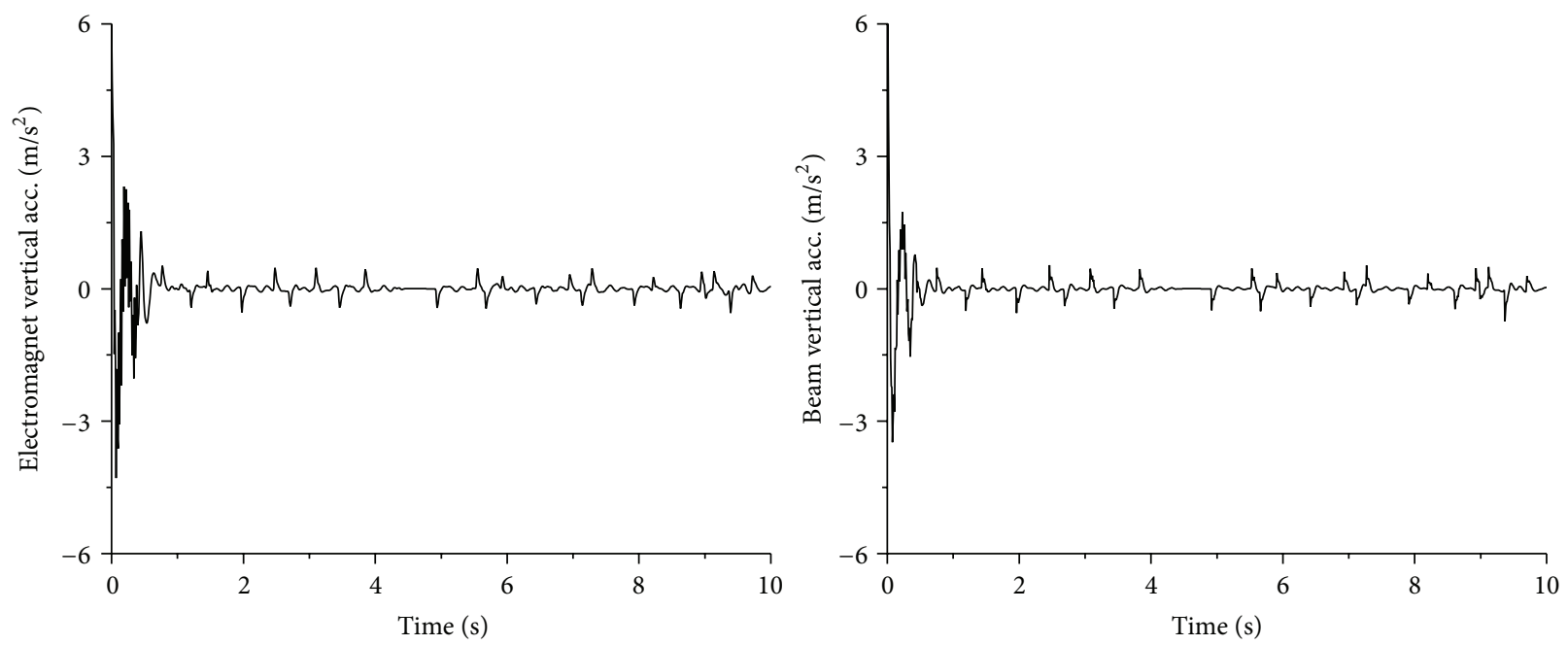

FIGURE 15: Vertical vibration of the electromagnet and track beam.
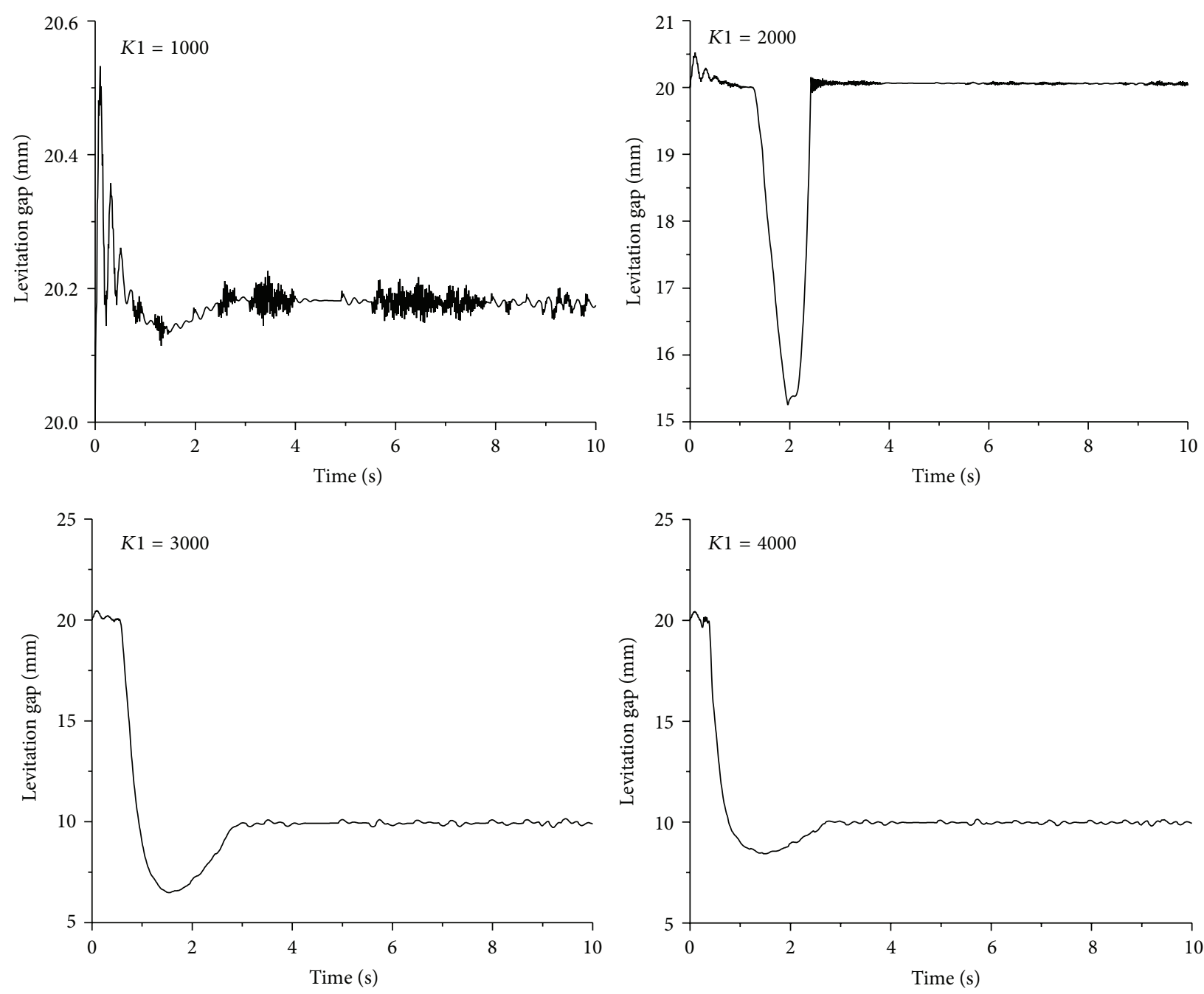

FIGURE 16: The levitation gap with different $K_{1}$ with the Shanghai track irregularity. 

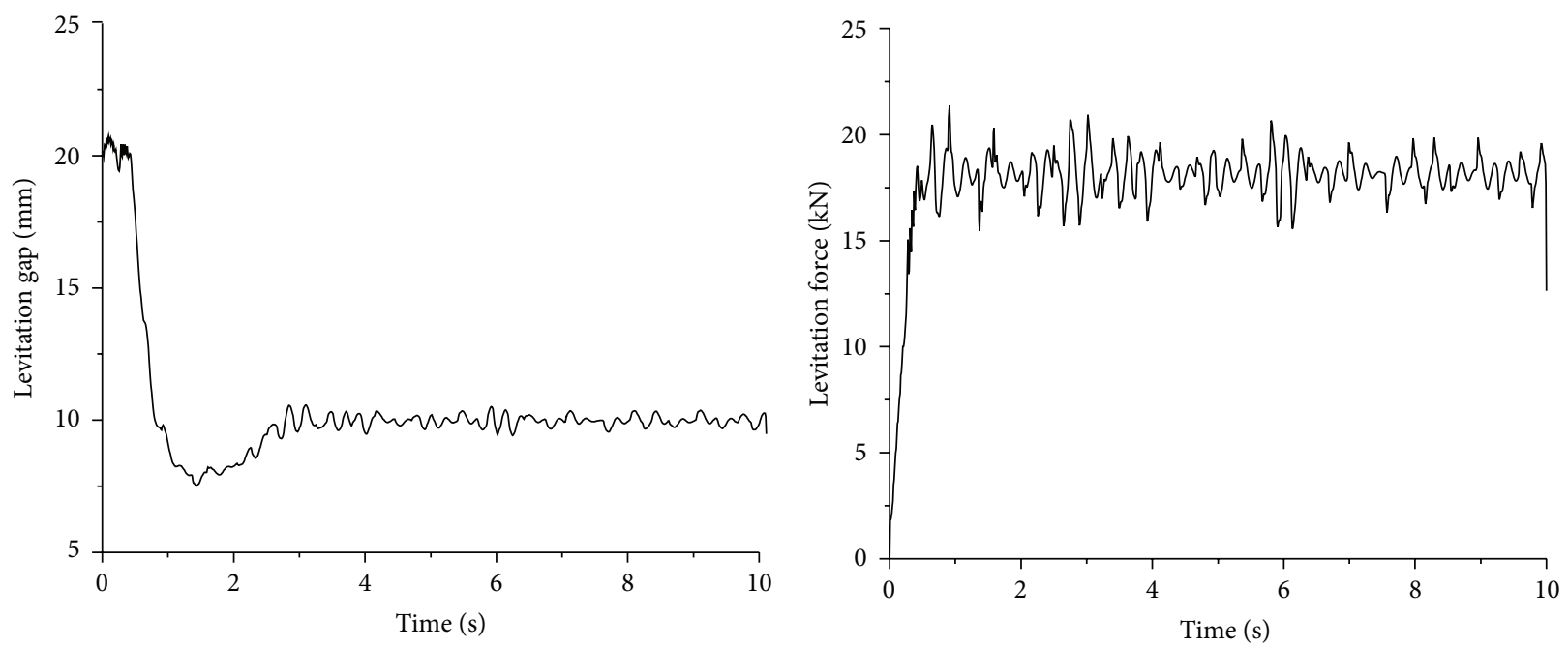

FIGURE 17: Levitation gap and levitation force.
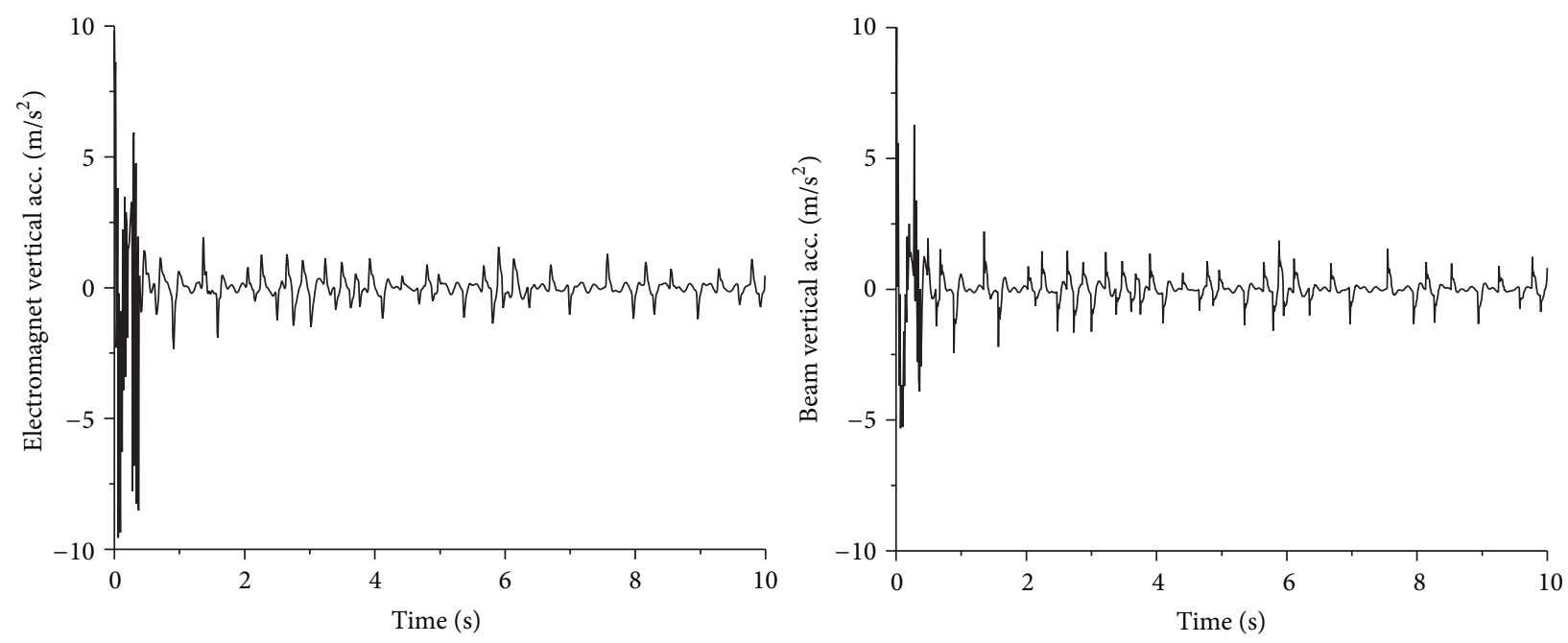

FIGURE 18: Vertical vibration of the electromagnet and track beam.

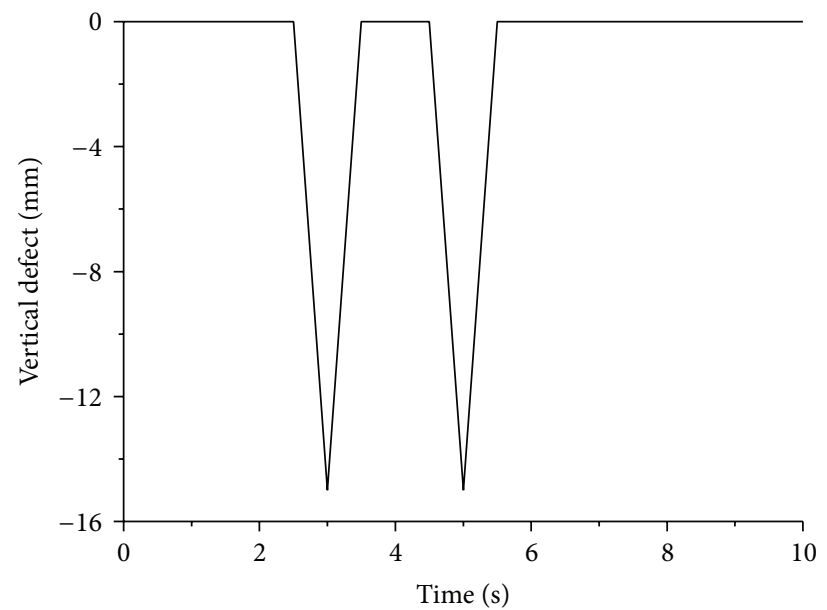

Figure 19: Track local support defect. 

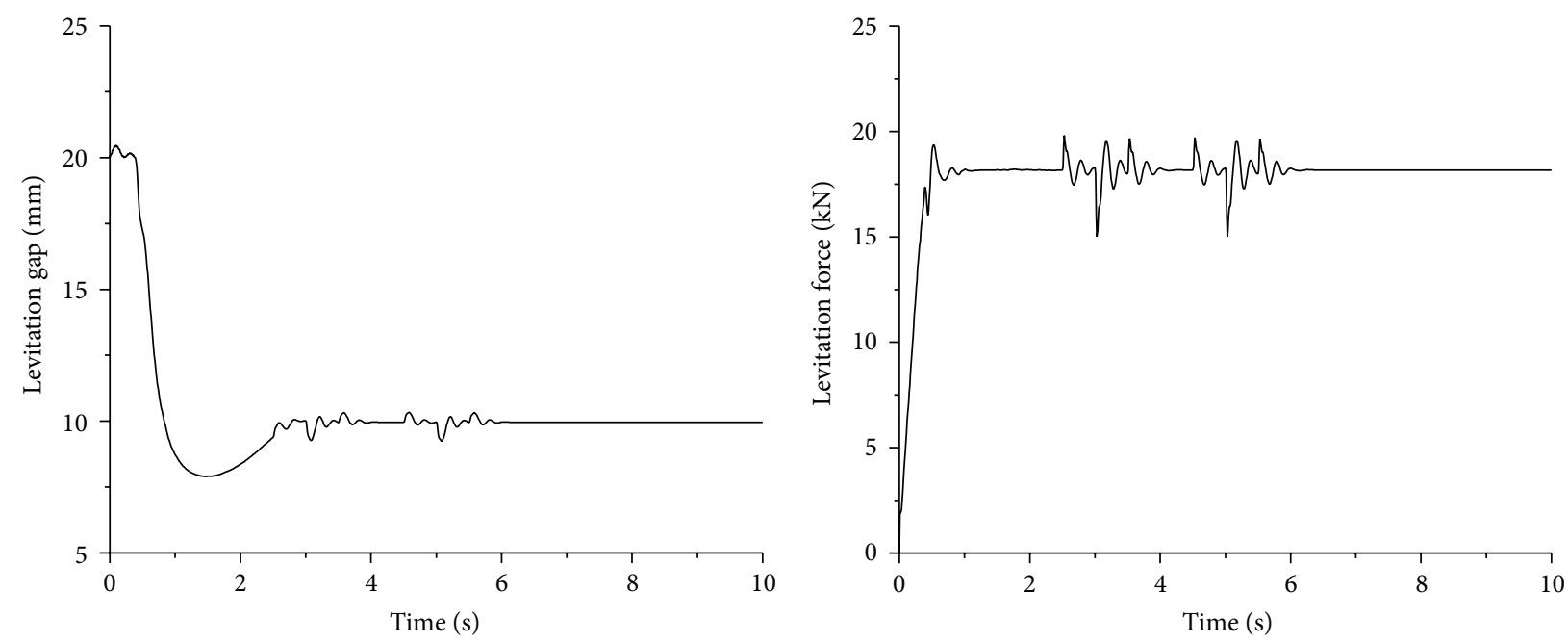

FIgURE 20: Levitation gap and levitation force.
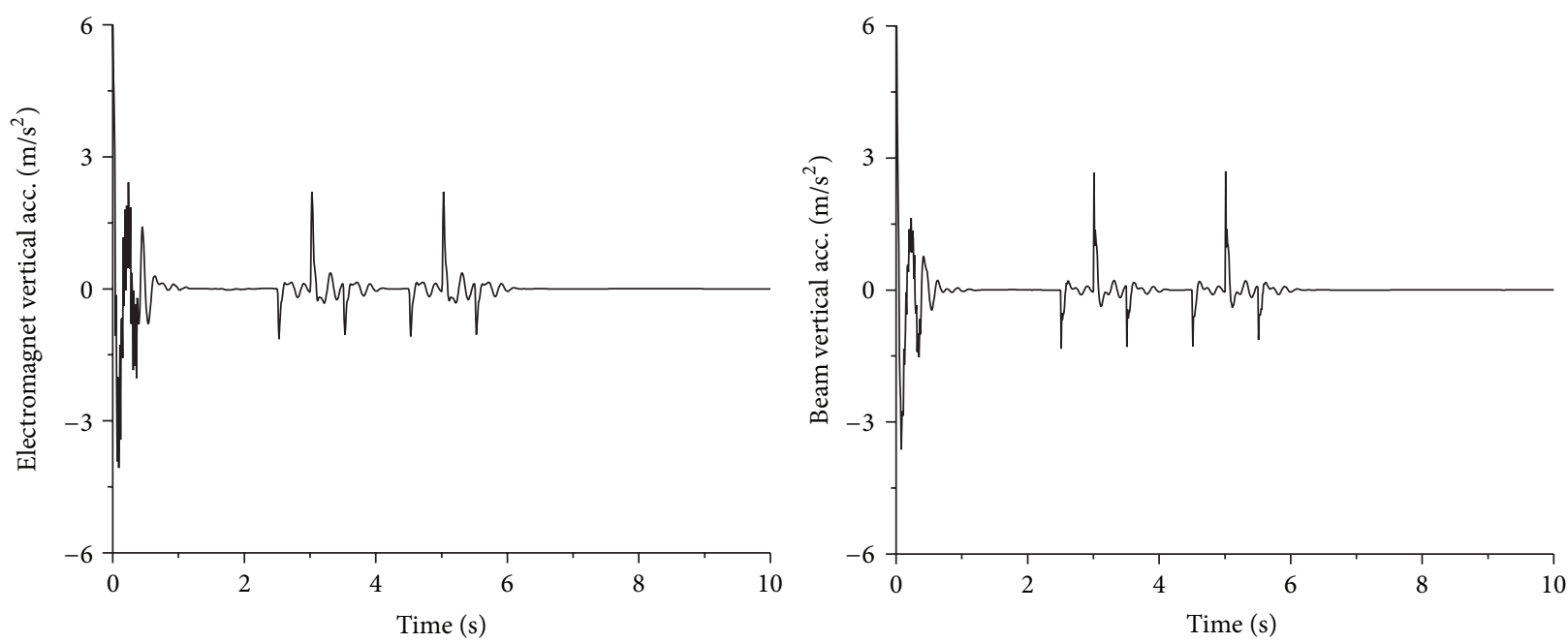

FIGURE 21: Vertical vibration of the electromagnet and the track beam.

be guided by the simulation results, and the experimental results can validate the dynamics simulation results, which can improve the dynamic simulation method.

The test bench will contribute to maglev vehicle development and accelerate the commercial process of implementing low-speed maglev trains.

\section{Conflict of Interests}

The authors declare that there is no conflict of interests regarding the publication of this paper.

\section{Acknowledgments}

The authors thank the National Natural Science Foundation of China (Grant no. 51005190) for their aid and support, the New Century Excellent Talents Program in University (Grant no. NCET-11-0712), the Science and Technology Project of Sichuan Province (Grant no. 2012GZ0103), the China Postdoctoral Science Foundation (Grant no. 2013M540715), and the "Sishi" Star Program of Southwest Jiaotong University.

\section{References}

[1] H. P. Wang, J. Li, and K. Zhang, "Vibration analysis of the maglev guideway with the moving load," Journal of Sound and Vibration, vol. 305, no. 4-5, pp. 621-640, 2007.

[2] Y. Gai, S. S. Chen, D. M. Rote, and H. T. Coffey, "Vehicle/guideway dynamic interaction in Maglev systems," Journal of Dynamic Systems, Measurement and Control, vol. 118, no. 3, pp. 526-530, 1996.

[3] H. P. Tang and F. Q. Gao, "Experimental research on dynamic characteristics and coupled vibration of a maglev train system," 
Journal of Southwest Jiaotong University, vol. 36, no. 2, pp. 149152, 2001.

[4] C. F. Zhao and W. M. Zhai, "Dynamic characteristics of a single magnet system applied to a low-speed EMS maglev vehicle," in Proceeding of the International Symposium on Speed-up and Service Technology for Railway and Maglev System, JSME no. 03205, pp. 472-477, Tokyo, Japan, 2003.

[5] X. J. Zheng, J. J. Wu, and Y.-H. Zhou, "Effect of spring nonlinearity on dynamic stability of a controlled maglev vehicle and its guideway system," Journal of Sound and Vibration, vol. 279, no. 1-2, pp. 201-215, 2005.

[6] H. S. Han, B. H. Yim, N. J. Lee, Y. C. Hur, and S. S. Kim, "Effects of the guideway's vibrational characteristics on the dynamics of a maglev vehicle," Vehicle System Dynamics, vol. 47, no. 3, pp. 309-324, 2009.

[7] J. D. Yau, "Vibration control of maglev vehicles traveling over a flexible guideway," Journal of Sound and Vibration, vol. 321, no. 1-2, pp. 184-200, 2009.

[8] S. Ren, A. Romeijn, and K. Klap, "Dynamic simulation of the maglev vehicle/guideway system," Journal of Bridge Engineering, vol. 15, no. 3, pp. 269-278, 2010.

[9] B. H. Yim, H. S. Han, J. K. Lee, and S. S. Kim, "Curving performance simulation of an EMS-type Maglev vehicle," Vehicle System Dynamics, vol. 47, no. 10, pp. 1287-1304, 2009.

[10] C. F. Zhao, W. M. Zhai, and K. Y. Wang, "Dynamic responses of the low speed maglev vehicle on the curved guideway," Vehicle System Dynamics, vol. 38, no. 3, pp. 185-210, 2002.

[11] D. Zhou, J. Li, and C. H. Hansen, "Suppression of the stationary maglev vehicle-bridge coupled resonance using a tuned mass damper," Journal of Vibration and Control, vol. 19, no. 2, pp. 191203, 2013.

[12] N. Hägele and F. Dignath, "Vertical dynamics of the maglev vehicle transrapid," Multibody System Dynamics, vol. 21, no. 3, pp. 213-231, 2009.

[13] E. Gottzein, R. Meisinger, and L. Miller, "The "magnetic wheel" in the suspension of high-speed ground transportation vehicle," IEEE Transactions on Vehicular Technology, vol. 29, no. 1, pp. 1723, 1980.

[14] P. K. Sinha, Electromagnetic Suspension Dynamic \& Control, Peter Peregrinus, 1987.

[15] M. Morita and M. Fujino, "State of levitation of linimo (HSST system) during EXPO2005," in Proceedings of the 19th International Conference on Magnetically Levitated Systems and Linear Drives (MAGLEV '06), pp. 309-312, Dresden, Germany, September 2006.

[16] X. M. Wu, Maglev Train, Shanghai Science and Technology Press, Shanghai, China, 2003.

[17] Y. H. Liu, G. S. Sun, and R. Wei, "The developmental status and future prospects of Maglev technology," in Proceedings of the 19th International Conference on Magnetically Levitated Systems and Linear Drives (Maglev '06), pp. 59-64, Dresden, Germany, September 2006.

[18] M. Takahashi, G. Kwok, and K. Kubota, "Marketing strategy of the HSST system," in Proceedings of the Maglev, pp. 53-57, 2006.

[19] X.-M. Wu, "Construction of Shanghai maglev demonstration line," Journal of Tongji University, vol. 30, no. 7, pp. 814-818, 2002.

[20] Y. Q. Deng, Static levitation stability researches and simulation of maglev [M.S. thesis], Southwest Jiaotong University, 2005.

[21] X. Liang, S.-H. Luo, W.-H. Ma, Q. Wu, and Z.-Q. Xu, "Coupling vibration analysis of single-magnet suspension vehicle-bridge for maglev train," Journal of Traffic and Transportation Engineering, vol. 12, no. 2, pp. 32-37, 2012.

[22] H. Hoshino, E. Suzuki, T. Yonezu, and K. Watanabe, "Examination of vehicle motion characteristics of a Maglev train set using a reduced-scale model experiment apparatus," Quarterly Report of Railway Technical Research Institute, vol. 53, no. 1, pp. 52-58, 2012.

[23] N. J. Lee, H. S. Han, J. M. Lee, and B. W. Kang, "Maglev vehicle/guideway dynamic interaction based on vibrational experiment," in Proceedings of the International Conference on Electrical Machines and Systems (ICEMS '07), pp. 1999-2003, Seoul, Korea, October 2007.

[24] J. D. Yau, "Response of a maglev vehicle moving on a series of guideways with differential settlement," Journal of Sound and Vibration, vol. 324, no. 3-5, pp. 816-831, 2009.

[25] J. Shi, Q. Wei, and Y. Zhao, "Analysis of dynamic response of the high-speed EMS maglev vehicle/guideway coupling system with random irregularity," Vehicle System Dynamics, vol. 45, no. 12, pp. 1077-1095, 2007. 

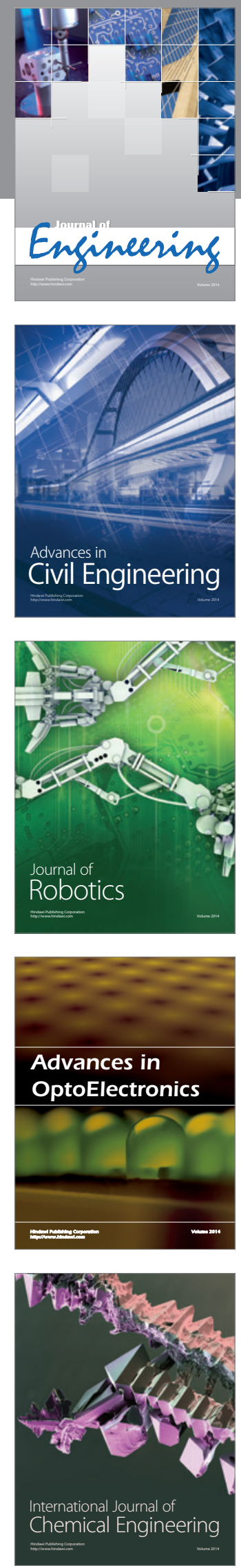

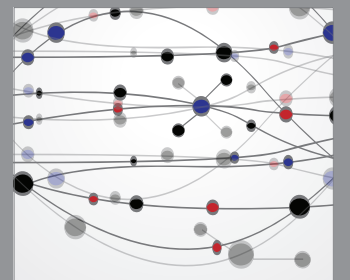

The Scientific World Journal
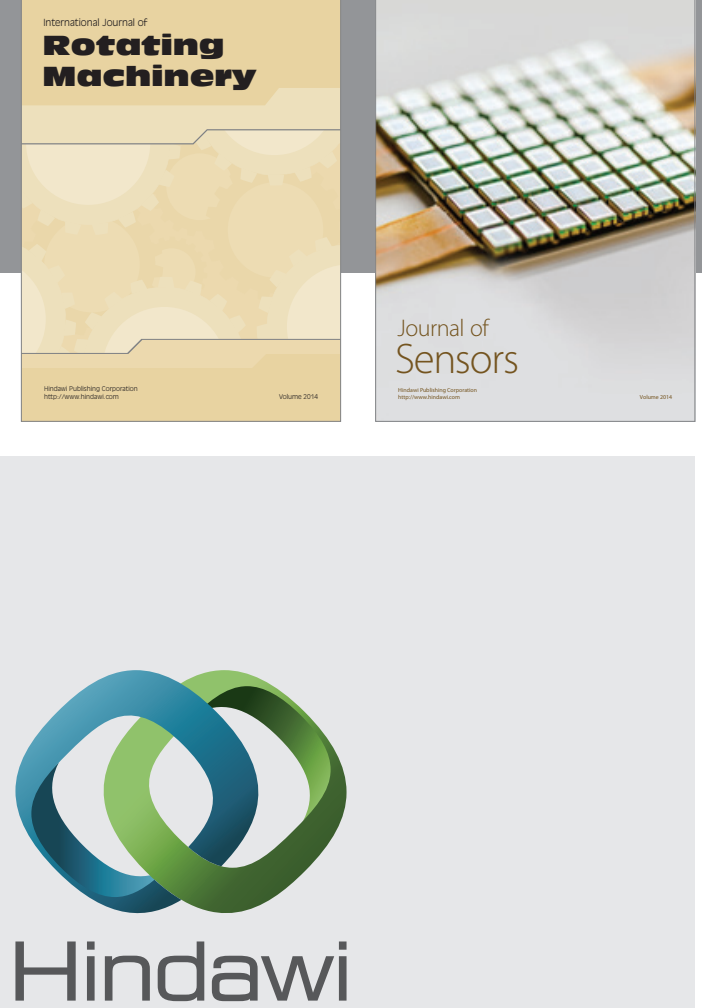

Submit your manuscripts at http://www.hindawi.com
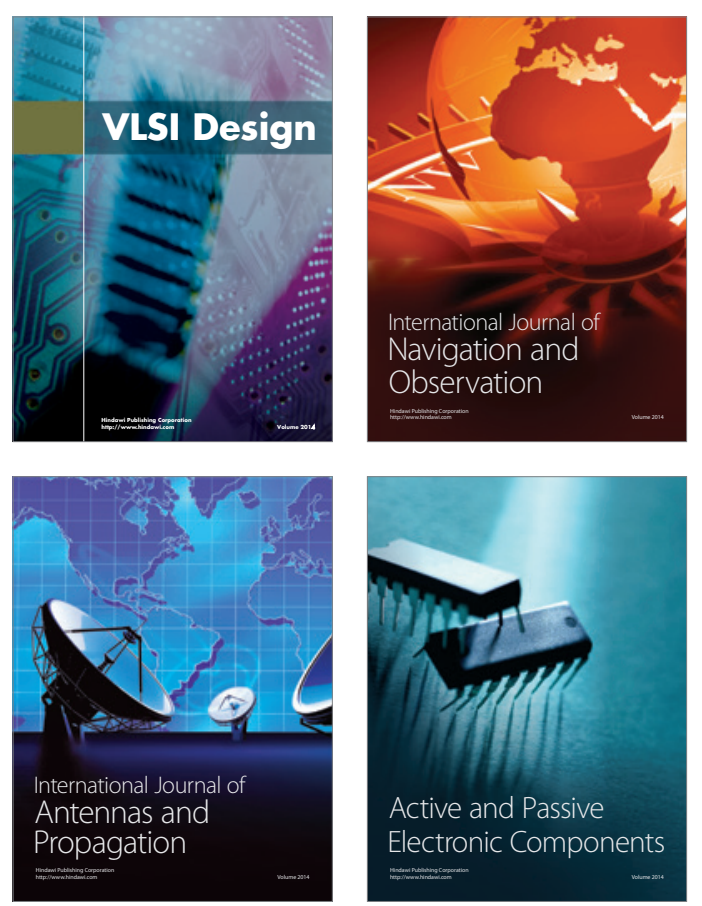
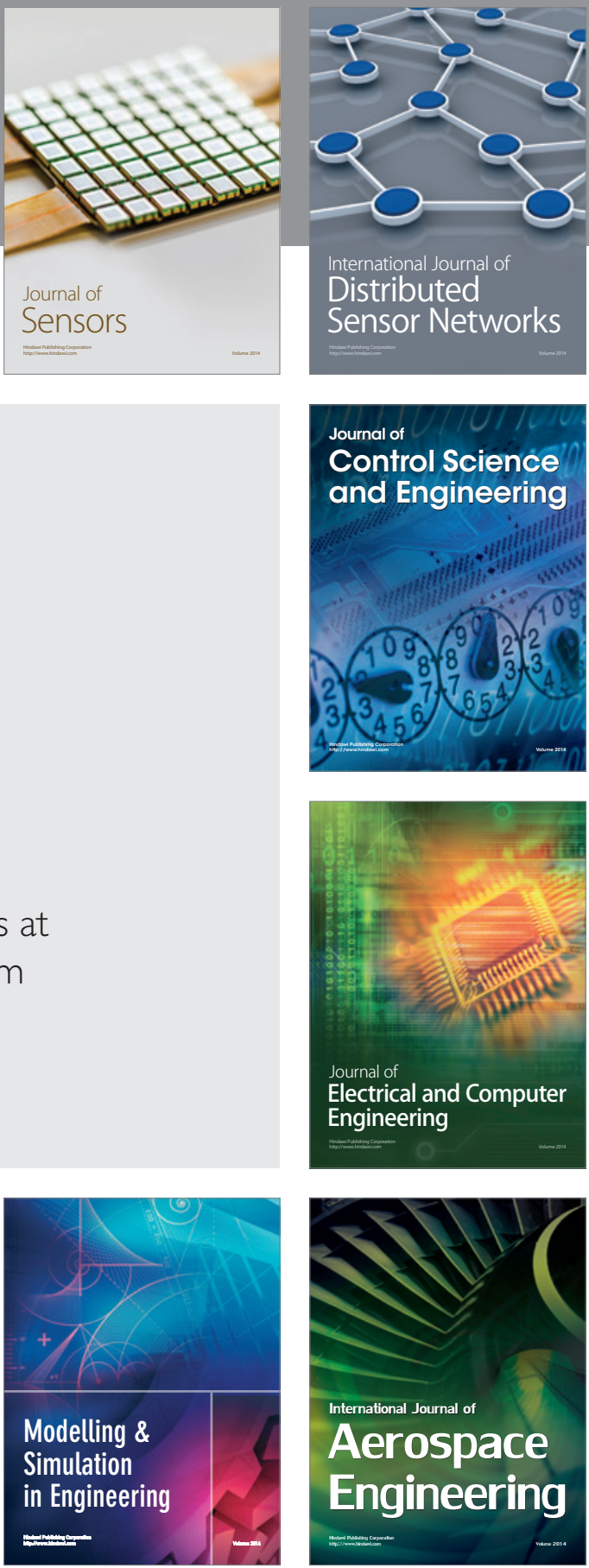

Journal of

Control Science

and Engineering
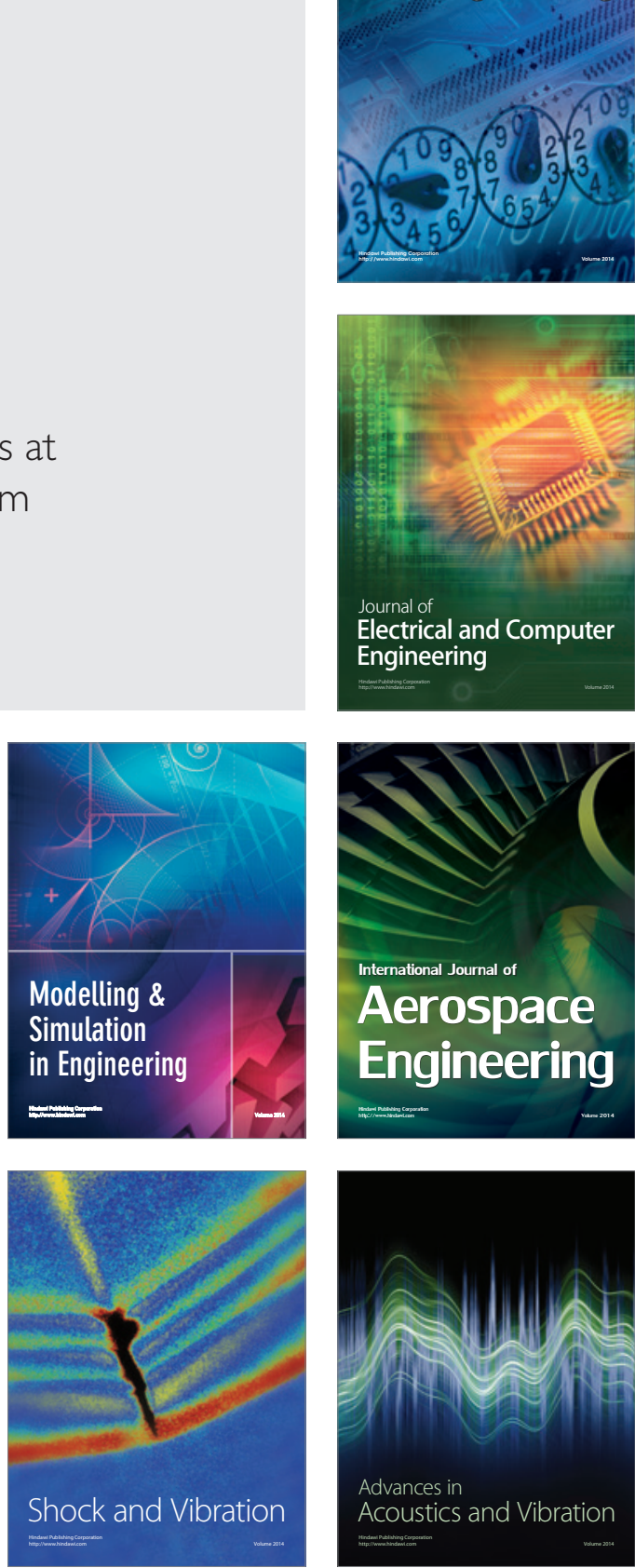